\title{
Gas Microstrip Detectors Based on Flexible Printed Circuit
}

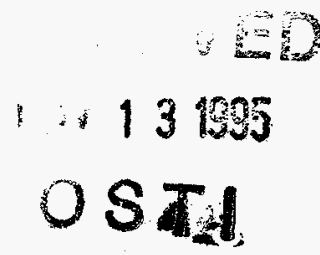

TRIUMF, 4004 Wesbrook Mall, Vancouver, B.C. Canada V6T 2A3

\section{Abstract}

We have studied the properties of a new type of Gas Microstrip Counter built using flexible printed circuit technology. We describe the manufacturing procedures, the assembly of the device, ass well as its operation under a variety of conditions, gases and types of radiation. We also describe two new passivation materials, Tantalum and Niobium, which produce effective surfaces.

\section{INTRODUCTION}

Microstrip Gas Detectors (MSGC's') were introduced some years ago [1] as position sensitive detectors capable of operating at very high rates. They consist of a substrate that supports metallic anode and cathode traces. This print, produced by some of the many lithographic methods available to present day technology, is immersed in a gas such as is used in wire chambers. An additional electrode establishes a drift field that forces the primary electrons, produced in the gas by an ionizing particle, to drift towards the anode-cathode plane. Recent publications $[2,3,4]$ describe these devices in detail.

Many different substrate materials have been tested so far. The substrate must be a high resistivity material to allow charges that build up on it to drift to the electrodes and avoid field distortions.. At the same time the substrate must sustain a large electric field in the vicinity of the anode to produce enough gas gain. Surface resistivities on the order of $10^{14}$ to $10^{15} \mathrm{Ohms} / \mathrm{square}$ have been found appropriate and have been realized with highly doped glasses [5-14], plastics with or without ion implantation $[8,9,12,15$ 23] and on thin $\mathrm{SiO}_{2}$ layers [7,24-27]. Most prints manufactured so far use integrated circuit technology for the etching process that produces the anodes and cathodes on the substrate. This allows anode to anode pitches down to 100 microns and line accuracies of a few microns, therefore producing devices with position sensitivity comparable to silicon strip detectors.

Due to the very small distance between anodes and cathodes the majority of the ions produced by the multiplication process in the vicinity of the anodes are drifted rapidly to the cathodes and the detector can operate at very high rates without field distortions produced by these ions. In fact, gas microstrip detectors are the only detectors that can maintain good efficiency in fluxes above $10^{6} / \mathrm{mm}^{2} /$ second $[6,14,21,29]$.

In this paper we present results of a gas microstrip detector built using a different type of technology, i.e. flexible printed circuit etching. The reasons for this choice are that large areas are possible (typically an order of magnitude larger in linear dimensions than previous devices), as well as a significant reduction in cost without compromising the performance of the device. A flexible substrate has the added advantages of low mass and of simplifying construction of cylindrical configurations. It should be pointed out that a somewhat similar method was realized previously [23].

In the next sections we will describe the manufacturing process, the properties of the devices with several types of passivation layers, gas gains for several gases, long term stability of operation and high rate performance as well as energy resolution for Xrays.

\section{CONSTRUCTION OF THE DETECTORS}

The pattern on our prints was designed using standard CAD methods with alternating anodes and cathodes of $90 \mu \mathrm{m}$ and $160 \mu \mathrm{m}$ width respectively, and a pitch of $800 \mu \mathrm{m}$. The cathodes are interconnected on the print and the anodes have individual pads. This design was sent to the manufacturer [30] who produced 120 similar prints on 4 sheets of "flexiprint" which is a layer of kapton [31] $70 \mu \mathrm{m}$ thick and a layer of copper $12 \mu \mathrm{m}$ thick. The etching technique was high resolution "wet-etch". The thickness of these traces is 5 to 10 times thicker than in standard GMSC's and this has two important advantages; a) it reduces the electric field on the cathode edges, reducing electron emission, and b) it eliminates the problem of the destruction of the traces due to large currents occurring in discharges. This was a serious problem in some early prints [19] which had thin aluminum traces.

On receiving the prints from the manufacturer, the surfaces were cleaned with isopropyl alcohol, polished with a fine abrasive and cleaned again. The polishing procedure is intended to remove sharp edges on the traces. The effect is shown in Fig. 1 which is the result of a profilometer [32] measurement on a print. 


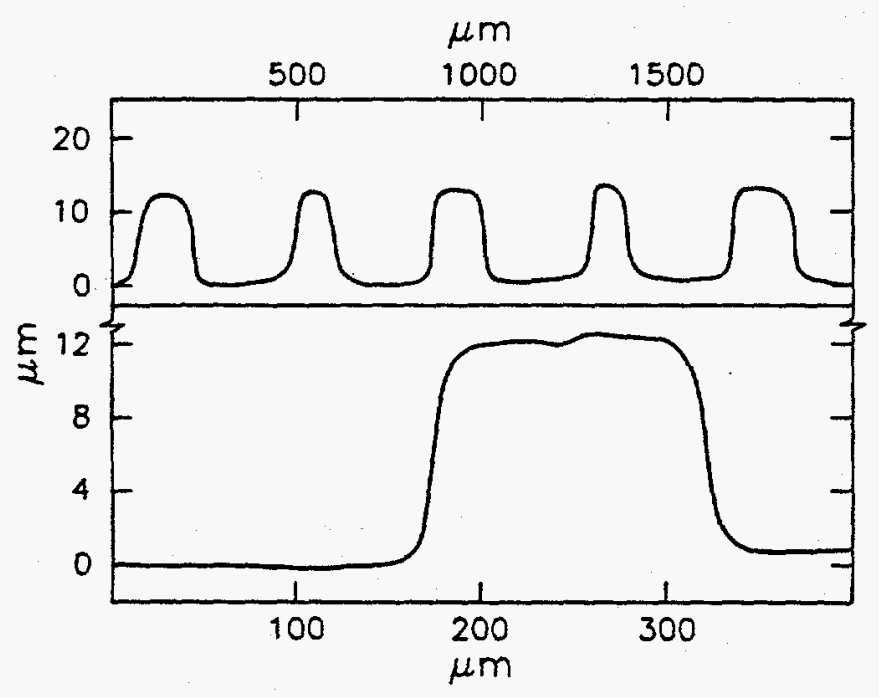

Fig 1. Results of a profilometer (Tencor Alpha-step 200) measurement on a print after the treatment described in Section 2. The bottom trace is a single cathode. Notice the different scales in the horizontal and vertical directions.

The next stage was the deposition of a passivation surface on the print [19], which accomplishes three functions; a) it provides a resistive layer for removal of unwanted charges on the insulating substrate, $b$ ) it protects the kapton near the anode from the very active ions generated in the multiplication process, and c) it covers the cathodes with an oxide layer which has lower secondary electron emission probability than the bare metal surface.



Fig 2. Measurements of the anode-cathode resistance of several prints passivated with Nickel, as a function of time.

We have tried the following metal surfaces: $\mathrm{Nb}$, $\mathrm{Ta}, \mathrm{Pb}, \mathrm{Cd}, \mathrm{Mo}, \mathrm{In}, \mathrm{Ni}$, and $\mathrm{Fe}$. We found that the best results were obtained with $\mathrm{Ni}, \mathrm{Ta}$, and $\mathrm{Nb}$. In all cases the deposition was accomplished by sputtering in an Argon atmosphere with $1.1 \mathrm{KV}$ in a DC mode. With these metals we could produce stable surfaces with the correct surface resistivity $\left(10^{13}\right.$ to
$10^{15} \mathrm{ohms} / \mathrm{square}$. Although the value of the resistivity changed with time, in all cases it stabilized after some days and did not change during the operation of the detectors. In Fig 2. we show the change of the resistivity after deposition.

The resistance of individual anodes was measured with respect to the common cathode to determine the uniformity of the passivation layer and found to be typically + or $-10 \%$, thereby insuring gain uniformity across the print. The print was then mounted on a print holder by means of a strip contact tape [34] applied by heat and pressure $\left(300 \mathrm{~g} / \mathrm{cm}^{2}\right.$, $200^{\circ} \mathrm{C}$ ). This procedure provided for electrical contact and mechanical support. The print holder was placed in the gas box which connects the anodes directly to the preamplifiers. The windows of the gas box were aluminized mylar. The preamplifier used in these tests is a Fermilab design QPA02 [35], having a gain of $1.4 \times 10^{-3} \mathrm{mV} / \mathrm{e}$ and a time constant of 30 ns. In Fig. 3 we show the amplitude spectrum of $\mathrm{X}$-rays from $\mathrm{Fe}^{55}$ source obtained with a print passivated with $\mathrm{Ni}$ in a gas mixture of argon/isobutane (90:10).

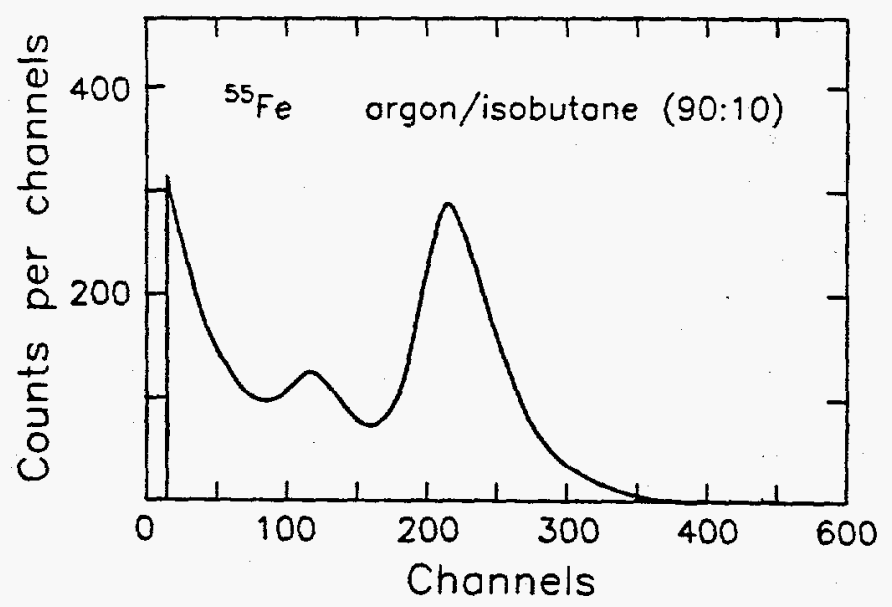

Fig 3. The pulse amplitude spectrum of X-rays emitted by a source of $\mathrm{Fe}^{55}$ using a gas mixture of argo/isobutane $(90: 10)$.

\section{PERFORMANCE WITH SEVERAL GASES}

In order to determine the best operating conditions we measured the gain with several gases, and in Figs. 4 and 5 we show the results for mixtures of argon/isobutane and argon $/ \mathrm{CO}_{2}$. The curves in Figs. 4 and 5 terminate at the highest cathode voltage before breakdown, which is initiated by electron emission from the cathode. Clearly both mixtures behave in a similar fashion. We also tested $\mathrm{CF}_{4}$ /isobutane because it is a fast gas $[33,36]$ and it has very good properties as a stable long term mixture in a high intensity environment. However, the absolute gas gain is about 10 times smaller at equivalent fields. 


\section{DISCLAIMER}

This report was prepared as an account of work sponsored by an agency of the United States Government. Neither the United States Giovernment nor any agency thereof, nor any of their employees, make any warranty, express or implied, or assumes any legal liability or responsibility for the accuracy, completeness, or usefulness of any information, apparatus, procluct, or process disclosed, or represents that its use would not infringe privately owned rights. Reference herein to any specific commercial product, process, or service by trade name, trademark, manufacturer, or otherwise does not necessarily constitute or imply its endorsement, recommendation, or favoring by the United States Government or any agency thereof. The views and opinions of authors expressed herein do not necessarily state or reflect those of the United States Government or any agency thereof. 


\section{DISCLAIMER}

Portions of this document may be illegible in electronic image products. Images are produced from the best available original document. 


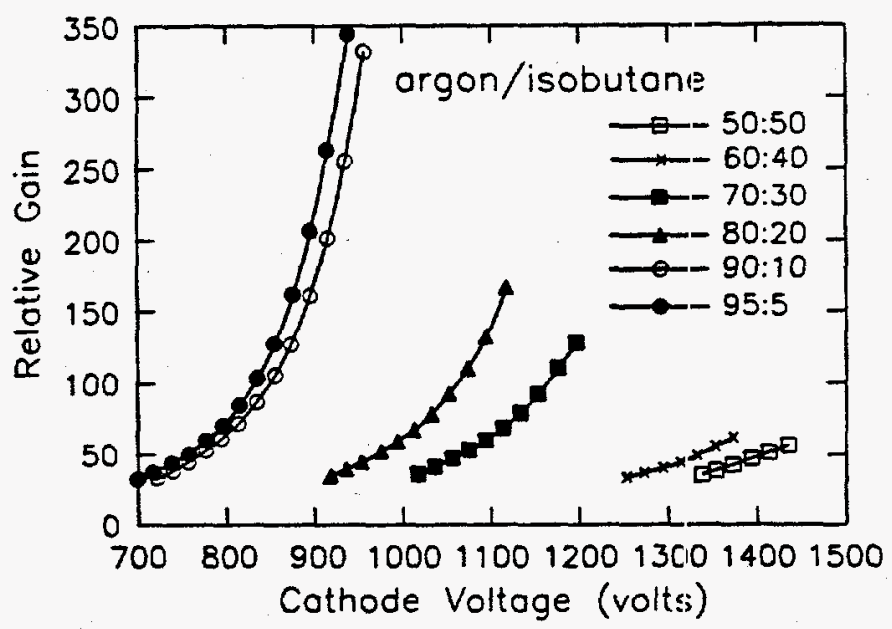

Fig 4. Gas gain vs. Anode cathode voltage for several gas mixtures of argon and isobutane.

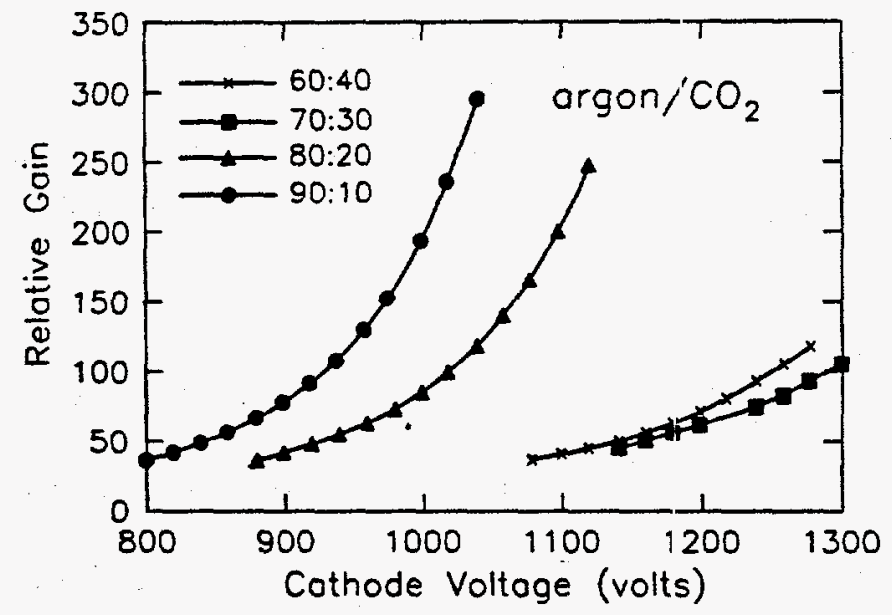

Fig 5. Gas gain vs. Anode cathode voltage for several gas mixtures of argon and $\mathrm{CO}_{2}$.

\section{HIGH INTENSITY CAPABILITY}

To measure the high rate capabilities of these detectors we used an X-ray generator operating at 10 to $40 \mathrm{kVolts}$ and currents up to $40 \mathrm{~mA}$. The gas used was $\mathrm{CF}_{4}$ /isobutane. (80:20). The flux was obtained with scalers at low rates and the current of the generator at high rates (they matched linearly at low rates). The relative gain was obtained from the logarithmic extrapolation of the bremsstrahlung end point. We used a small collimator of $2 \mathrm{~mm}$ diameter to define the X-ray beam and scaled the pulses of one anode only. Measurements were done with sources at low rates and matched to the data from the generator. The result is shown in Fig. 6 and indicates stable operation up to fluxes of $5 \times 10^{5} \mathrm{~Hz} / \mathrm{mm}^{2}$. This value is lower than the best measurements [14] done recently with GMSC's, because of the larger pitch of this detector, but it is still an order of magnitude higher than the best results obtain with standard wire chambers [33].

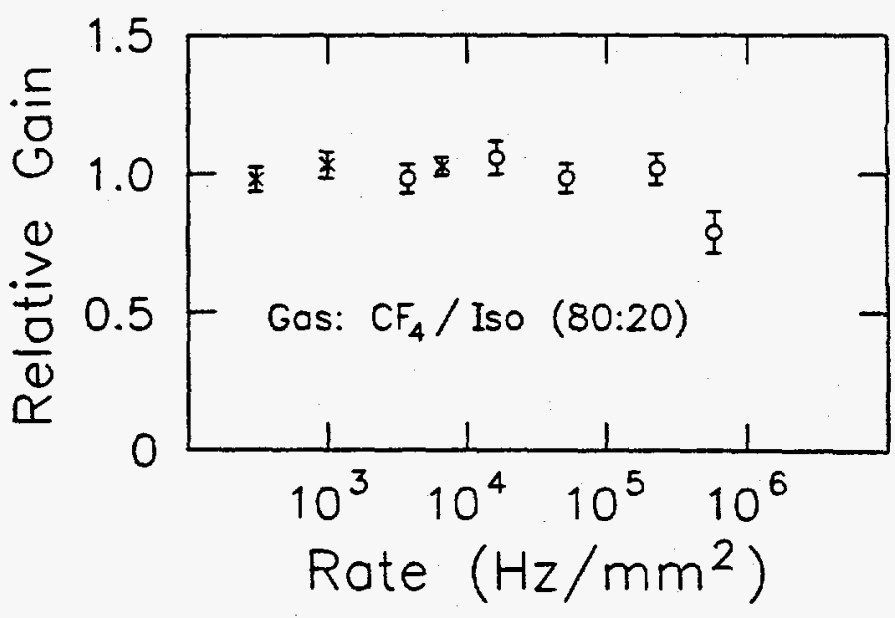

Fig 6. Relative gas gain vs. the flux of X-rays measured with sources $(x)$ and an $X$-ray generator (o) operating at $40 \mathrm{kV}$ and currents up to $30 \mathrm{~mA}$.

\section{LONG TERM PERFORMANCE}

It is important that a detector operating at high rates can maintain its properties such as gain and resolution etc. over long periods of operation. This has been a problem for some types of gaseous detectors, in part due to gas breakdown in the avalanche region, with a consequent deposit of solids on the anode structures. This in turn reduces the gain and impairs the performance of the detector. We tested this effect in the MSGC's described above. In particular we used a gas mixture which proved successful in past experiments in wire chambers because of its property of removing these deposits. Mixtures of $\mathrm{CF}_{4}$ /isobutane have been shown [36] to have these properties, and indeed they show very good results with GMSC's.

\section{Charge $(\mathrm{mC} / \mathrm{cm})$}

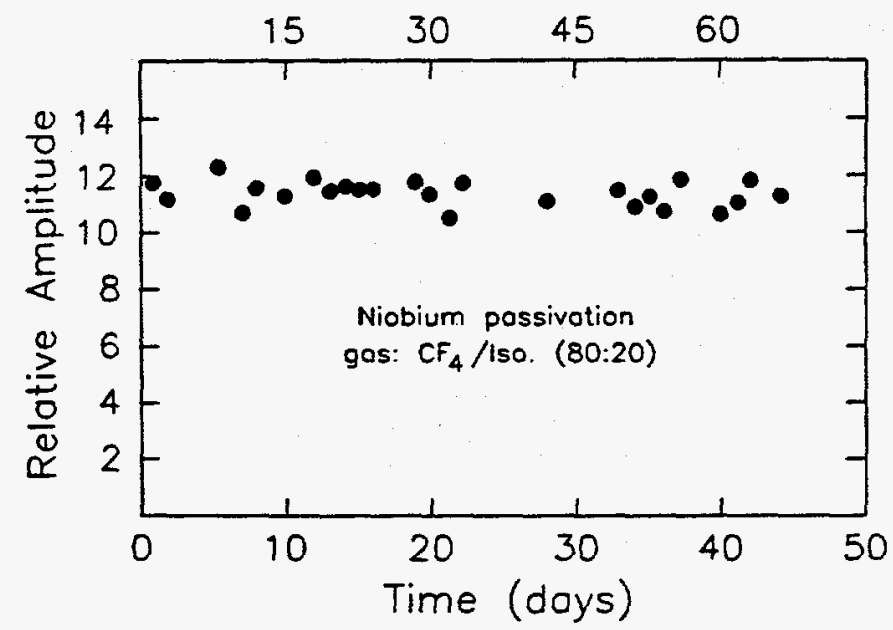

Fig 7. Relative gas gain of a GMSC operating for 45 days in a continuous high intensity environment as described in section 5 . In this case the print was passivated with Niobium. 
In Fig. 7 we show the gain of our detector in such a gas, performed over a period of 46 days with a high intensity $\mathrm{Sr}^{90}$ source. The chamber ran at a rate of $10^{5} /$ second uninterrupted during this period accumulating a total charge of $70 \mathrm{mC} / \mathrm{cm}$ of anode and the gain remained constant during this period. In this case the passivating layer was $\mathrm{Nb}$, but similar results have been obtained previously [12] for $\mathrm{Ni}$ passivation.

No visible signs of damage or discolouration were seen on the print when inspected under a microscope.

\section{CONCLUSIONS}

We have studied the properties of GMSC's made on flexible printed circuit and using printed circuit etching technology, and found that they operate quite successfully. Although they cannot achieve the small pitch available using integrated circuit technology, the performance is improved compared with standard wire chambers on several aspects. They operate at high rates, are easier to manufacture and the geometry of anodes and cathodes can be suited to individual experimental needs. They are also less costly than standard wire chambers, and can be mass produced thereby opening possible applications in the field of X-ray imaging.

Long term performance is similar to results obtained with conventional GMSC's, with charge densities of $0.2 \mathrm{C} / \mathrm{cm}$ obtained without significant degradation in the gain or the physical structure of the prints.

Several gases have been studied, including argon $/ \mathrm{CO}_{2}$ which has high gain and the advantage of being non-flammable.

Three metal passivation coatings have been shown to provide a good passivation surface with the desired properties, i.e. Niobium, Nickel and Tantalum.

\section{REFERENCES}

[1] A. Oed, Nucl. Instr. and Meth. A263(1988)351

[2] R. Bouclier et al., Nucl. Instr. and Meth. A332(1993)100 and references therein.

[3] F. Angelini et al., Nucl. Instr. and Meth. A315(1992)21 and references therein.

[4] International Workshop on Microstrip Gas Chambers, Legnaro, Italy, October 1994. Editors: G. Della Mea, F. Sauli.

[5] F. Hartjes et al., Nucl. Instr. and Meth. A310(1991)88

[6] R. Bouclier et al., Nucl. Instr. and Meth. A323(1992)240.

[7] A.F. Barbosa, Nucl. Instr. and Meth. A323(1992)247.

[8] E.F. Barash, Nucl. Instr. and Meth. A315(1992)170.
[9] F. Angelini et al., Nucl. Instr. and Meth. A336(1993)106.

[10] A. Breskin et al., Nucl. Instr. and Meth. A345(1994)205.

[11] D. Anderson et al., Nucl. Instr. and Meth. A346(1994)102.

[12] M. Salomon et al., Nucl. Instr. and Meth. A351(1994)313.

[13] M.H.G. Geijsberts et al., NIKEF -/91-21 and /91-23.

[14] R. Bouclier et al., CERN-PPE/95-95.

[15] R. Bouclier et al., CERN-PPE/91-108.

[16] R. Bouclier et al., IEEE NS-39(1992)650.

[17] R. Bouclier et al., Nucl. Instr. and Meth. A310(1991)74.

[18] T. Nagae et al., Nucl. Instr. and Meth. A323(1992)236.

[19] M. Salomon et al., IEEE NS-41 (1994)817.

[20] S. Brons et al., CERN-PPE/93-194.

[21] J. Dubeau et al., Vienna WCC95 Conf. Feb 1995.

[22] J.H. Moromisato, Legnaro MSGC Workshop (see Ref. 4)

[23] J.H. Moromisato, Nucl. Instr. and Meth. A345(1994)90.

[24] F. Angelini et al., Nucl. Instr. and Meth. A314(1992)450.

[25] S.F. Biagi et al., Nucl. Instr. and Meth. A323(1992)258.

[26] F. Angelini et al., Nucl. Instr. and Meth. A336(1993)69.

[27] F. Angelini et al., Legnaro MSGC's Workshop (see Ref. 4)

[28] R. Bouclier et al., CERN-PPE/95-9.

[29] J. Bohm et al., CERN-PPE/94-115.

[30] Merix Corporation, Oregon, USA.

[31] Kapton is a polyimide manufactured by Dupont.

[32] Tencor Alpha-step 200.

[33] R. Henderson et al., IEEE NS-34 (1987)528.

[34] Elform bonding tape, Reno, Nevada, USA.

[35] T. Zimmerman, IEEE NS-37(1990) 439.

[36] R. Openshaw et al., Nucl. Instr. and Meth. A307(1991)298. 